\title{
Cytotoxic effects of propiconazole and its metabolites in mouse and human hepatoma cells and primary mouse hepatocytes
}

\author{
Pei-Jen Chen ${ }^{\mathrm{a}, \mathrm{b}}$, Tanya Moore ${ }^{\mathrm{b}}$, Stephen Nesnow ${ }^{\mathrm{b}, *}$ \\ a Department of Agricultural Chemistry, National Taiwan University, Taipei, Taiwan \\ ${ }^{\mathrm{b}}$ Environmental Carcinogenesis Division, National Health and Environmental Effects Research Laboratory, US Environmental Protection Agency, B143-06, \\ 109 T.W. Alexander Drive, Research Triangle Park, NC 27711, USA
}

\section{A R T I C L E I N F O}

\section{Article history:}

Received 12 February 2008

Accepted 7 May 2008

Available online 13 May 2008

\section{Keywords}

Propiconazole

Conazole

Hepa1c1c7

HepG2

Primary mouse hepatocytes

Cytotoxicity

LogP

MTT

Neutral red

\begin{abstract}
A B S T R A C T
Propiconazole is a triazole-containing fungicide that is used agriculturally on grasses, fruits, grains, seeds, hardwoods, and conifers. Propiconazole is a mouse liver hepatotoxicant and a hepatocarcinogen that has adverse reproductive and developmental toxicities in experimental animals. The goal of this study was to investigate the cytotoxic responses of propiconazole and its metabolites to determine if metabolism of this agent differentially affected its cytotoxic activities in hepatic tumor cell lines and in primary hepatocytes. To this end the cytotoxic effects of propiconazole and five of its metabolites were examined in three hepatic cell types: The mouse hepatoma Hepa1c1c7 cell line, the human hepatoma HepG2 cell line, and primary cultures of mouse hepatocytes. We initially compared the responses of propiconazole exposure in both Hepa1c1c7 and HepG2 cell lines over a concentration range of $0-200 \mu \mathrm{M}$ using two assay systems: The 3-(4,5-dimethylthiazol-2-yl)-2,5-diphenyltetrazolium bromide (MTT) assay and the neutral red assay. Concentration-related cytotoxic responses were evident in both cell lines using both endpoints with the MTT assay providing enhanced sensitivity.

The relative cytotoxic effects of propiconazole and five propiconazole metabolites were further assessed by the MTT assay using Hepa1c1c7 and HepG2 tumor cell lines. The cell cultures were exposed to various concentrations of propiconazole and five of its metabolites over a range of $0-400 \mu \mathrm{M}$. Propiconazole was cytotoxic in both cell lines in a dose-dependent manner. All five metabolites were less cytotoxic in both cell lines compared to the parent compound. The most cytotoxic metabolites in Hepa1c1c7 and HepG2 cells among the five were 3-(2-((1H-1,2,4-triazol-1-yl)methyl)-2-(2,4-dichlorophenyl)-1,3-dioxolan-4-yl)propan-1-ol and 1-(2-((1H-1,2,4-triazol-1-yl)methyl)-2-(2,4-dichlorophenyl)-1,3-dioxolan-4-yl)propan-2-ol. Propiconazole was cytotoxic in primary mouse hepatocytes; however none of the five propiconazole metabolites exerted cytotoxic activities. There was a linear relationship between the cLogP and the cytotoxic effects of propiconazole and its five metabolites in Hepa1c1c7 cells.

We conclude that these propiconazole metabolites would not contribute to the propiconazole-induced cytotoxicity process in primary mouse hepatocytes. Furthermore, since in tumor cell lines the metabolites were less cytotoxic than the parent propiconazole, our results suggest that in the tumorigenesis process as tumor cells are formed they would be more susceptible to the cytotoxic effects of propiconazole compared to the metabolites.
\end{abstract}

Published by Elsevier Ltd.
Abbreviations: MTT, 3-(4,5-dimethylthiazol-2-yl)-2,5-diphenyltetrazolium bromide; cLogP, calculated LogP (log of the octanol-water partition coefficient).

The research described in this article was reviewed by the National Health and Environmental Effects Research Laboratory, EPA, and approved for publication. Approval does not signify that the contents necessarily reflect the views and policies of the Agency, nor does mention of trade names or commercial products constitute endorsement or recommendation of use.

* Corresponding author. Tel.: +1 919541 3847; fax: +1 9195410694.

E-mail address: nesnow.stephen@epa.gov (S. Nesnow).

\section{Introduction}

Propiconazole ( $\pm-(1-[[2-(2,4-d i c h l o r o p h e n y l)-4-p r o p y l-1,3-$ dioxolan-2-yl]methyl]-1H-1,2,4-triazole, TILT) is an environmentally-important triazole systemic fungicide. Propiconazole is a member of a class of conazole fungicides that contain the 1,2,4-triazole moiety. It has fungicidal activity that protects against powdery mildew, rusts, and leaf spot disease (INCHEM, 1987). While conazoles are designed to protect crops from fungal infections, many have adverse effects in other organisms. For example, fenbuconazole, triadimefon, and imazilil each induce thyroid and liver tumors in rodents (INCHEM, 1981, 1997, 2001). Propiconazole can exert adverse 
effects in mammals, fish, insects, mollusks, and zooplankton (INCHEM, 1987; Pesticideinfo.org, 2008). Mice fed propiconazole for two years, developed hepatocellular adenomas and carcinomas, while rats did not develop tumors (INCHEM, 1987). Propiconazole was also demonstrated to promote the formation of hepatic preneoplastic foci in rats after dimethylnitrosamine treatment (Hakoi et al., 1992). Propiconazole induced hepatomegaly in both mice and rats after daily gavage at $150 \mathrm{mg} / \mathrm{kg}$ and hepatic necrosis in rats at $450 \mathrm{mg} / \mathrm{kg}$ doses (INCHEM, 1987; Sun et al., 2005).

The metabolism of xenobiotics can be considered as a detoxification process converting lipophilic substances to less toxic water soluble forms through oxidation, and conjugation and then excretion of these molecules. However, some xenobiotics undergo metabolism of the parent molecule to more toxic metabolites, and this process of metabolic activation is considered to be a key component of their toxicity pathways. This has been demonstrated for polycyclic aromatic hydrocarbons, aromatic amines, and nitrosamines (Miller and Miller, 1983; Xue and Warshawsky, 2005). Some pesticides also demonstrate this requirement. Thiamethoxam and several chloroacetanilides are some examples. Thiamethoxam metabolites are more hepatotoxic than thiamethoxam itself and are key metabolic intermediates in the formation of mouse liver tumors (Green et al., 2005a,b; Pastoor et al., 2005). The chloroacetanilides alachlor and acetochlor, both induce nasal tumors in rats through metabolism to reactive quinone-imine metabolites. These metabolites bind to nasal proteins which induce cytotoxicity, cell death, compensatory hyperplasia, and nasal adenomas (Green et al., 2000).

The metabolism of propiconazole has been studied in mammals. Metabolism can occur at the propyl side chain leading to a series of alcohols, acids, and $\alpha$-hydroxy-carboxy acids and by cleavage of the dioxolone ring (INCHEM, 1987).

The goal of this study was to investigate the cytotoxic responses of propiconazole and its metabolites to determine if metabolism of this agent differentially affected its cytotoxic activities in hepatic tumor cell lines and in primary hepatocytes. We approached this goal by evaluating the cytotoxic effects of known propiconazole metabolites and comparing their effects to that of propiconazole (Fig. 1). We employed a mouse hepatoma cell line (Hepa1c1c7), primary mouse hepatocytes, as well as a human hepatoma cell line (HepG2) in these investigations. We used two cytotoxicity bioassays, the 3-(4,5-dimethylthiazol-2-yl)-2,5-diphenyltetrazolium bromide (MTT) bioassay and the neutral red bioassay to compare the cytotoxic effects of propiconazole, and the MTT bioassay to examine the cytotoxic effects of the propiconazole metabolites. MTT is a water soluble yellow tetrazolium dye, which is reduced to the water insoluble purple formazan in the mitochondria of living cells. This reduction takes place only when mitochondrial reductase enzymes are active, and therefore conversion is directly related to the number of viable cells (Mosmann, 1983). Neutral red is eurhodin dye and a vital stain that readily penetrates cell membranes by nonionic diffusion, accumulating in the cell. Damaged or dead cells lose their ability to retain neutral red which is then removed during the wash procedure. Cell viability is related to the quantity of extracted dye from the intact viable cells (Borenfreund and Puerner, 1984).

We found that all five metabolites were less cytotoxic compared to the parent propiconazole in each cell type suggesting that these metabolites of propiconazole would not play a significant role in propiconazole induced hepatic toxicity in both normal and tumor cells.

\section{Material and methods}

\subsection{Chemicals and reagents}

Propiconazole was a gift of Syngenta Crop Protection Inc. (Greensboro, NC). Five propiconazole metabolites (CGA 118244,
CGA 118245, CGA 91304, CGA 91305, and CGA 136735) were provided by Dr. John Kenneke (US EPA, National Exposure Research Laboratory-Athens). Culture flasks and plates were purchased from Corning Inc. (Corning, NY). Eagle's Minimum Essential Medium (EMEM) (containing $2 \mathrm{mM}$ L-glutamine, $1.0 \mathrm{mM}$ sodium pyruvate, $0.1 \mathrm{mM}$ nonessential amino acids, and $1.5 \mathrm{~g} /$ L sodium bicarbonate), Alpha Minimum Essential Medium (AMEM) (containing $1.5 \mathrm{~g} / \mathrm{L}$ sodium bicarbonate without nucleosides), and fetal bovine serum (FBS) were obtained from the American Type Culture Collection (ATCC, Rockville, MD, USA). Williams E Medium (WEM) supplemented with $5 \mathrm{U} / \mathrm{ml}$ penicillin, $5 \mu \mathrm{g} / \mathrm{ml}$ streptomycin, $0.1 \mu \mathrm{M}$ dexamethasone, ITS+ (insulin, transferrin, and selenium complex), L-glutamine, and HEPES were purchased from CellzDirect, Inc. (Pittsboro, NC). Trypsin-EDTA $(0.25 \%(\mathrm{w} / \mathrm{v})$ trypsin-0.53 mM EDTA) and phosphate-buffered saline (PBS) and Dubecco's PBS (D-PBS) were obtained from Gibco (Grand Island, NY). Acetone, benzo[a]pyrene, neutral red, and MTT were purchased from Sigma-Aldrich Chemical Co. (St. Louis, MO).

\subsection{Cell lines and culture}

The human hepatoma cell line (HepG2) and the mouse hepatoma cell line (Hepa1c1c7) were obtained from the ATCC. HepG2 cells (passage 82-86) were grown in $25 \mathrm{~cm}^{2}$ culture flasks in EMEM supplemented with $10 \% \mathrm{FBS}$, at $37{ }^{\circ} \mathrm{C}$ in a humidified $5 \%$ $\mathrm{CO}_{2} / 95 \%$ air atmosphere. Media were changed every 3-4 days and cells were passaged when reached to $80-90 \%$ confluence. To subculture cells, the culture medium was aspirated and cells were briefly washed with PBS and $0.25 \%(\mathrm{w} / \mathrm{v}$ ) Trypsin-0.53 mM EDTA before incubation with trypsin-EDTA $(1 \mathrm{ml})$ for 5-10 min. The detached cells were passed through a 25 gauge, $5 / 8$ " needle attached to a $1 \mathrm{ml}$ tuberculin syringe (BD Bioscience, San Jose, CA) to separate clumps of cells, and appropriate aliquots of the cell suspension were added to the EMEM supplemented with $10 \%$ FBS with a subcultivation ratio of $1: 4$. The culturing procedure for Hep1c1c7 cells was performed as described above except that the Hep1c1c7 cells were grown in AMEM supplemented with $10 \%$ FBS using cell passage $10-15$, and with a sub-cultivation ratio of $1: 10$. Pre-plated fresh primary mouse hepatocytes (approximately 26,000/well) from male $C D-1$ mice (eight week old) from each of three mice were obtained from CellzDirect (Durham, NC) and were preserved in cold preservation media in 96-well microtiter plates.

\subsection{Cell viability assays}

\subsubsection{Neutral red assay}

The method used was described by Borenfreund and Puerner (Borenfreund and Puerner, 1984). Briefly, Hepa1c1c7 cells were seeded in 96-well plates at a density of $3 \times 10^{3}$ cells/well in $200 \mu \mathrm{L}$ of AMEM supplemented with $10 \% \mathrm{FBS}$, and incubated at $37{ }^{\circ} \mathrm{C}$ in $5 \% \mathrm{CO}_{2} / 95 \%$ air. When cells reached $60-70 \%$ confluence ( $\sim 24 \mathrm{~h})$, non-adherent cells and serum-containing AMEM were removed and propiconazole-treated serum-free AMEM were applied. Propiconazole-treated stocks were initially prepared in acetone, and diluted with serum-free AMEM to the appropriate concentration for each experiment. The final acetone concentration did not exceed $0.5 \%$. The cells were then treated with various concentrations of the propiconazole-treated serum-free AMEM stocks for $24 \mathrm{~h}$. At the end of the treatment period the media was removed and replaced with $250 \mu \mathrm{L}$ fresh warm D-PBS. Serum-free AMEM medium containing $0.003 \%$ neutral red dye was added $(200 \mu \mathrm{L}$ per well). After a $3-\mathrm{h}$ incubation at $37^{\circ} \mathrm{C}$, the neutral red medium was decanted and each well was rinsed once with $200 \mu \mathrm{L}$ warm DPBS. The neutral red dye taken up by viable cells was extracted with $100 \mu \mathrm{L}$ of ethanol/acetic acid ( $1 \%$ glacial acetic acid solution, $50 \%$ ethanol, $49 \% \mathrm{H}_{2} \mathrm{O}$ ) for $30 \mathrm{~min}$ with gentle shaking protected 


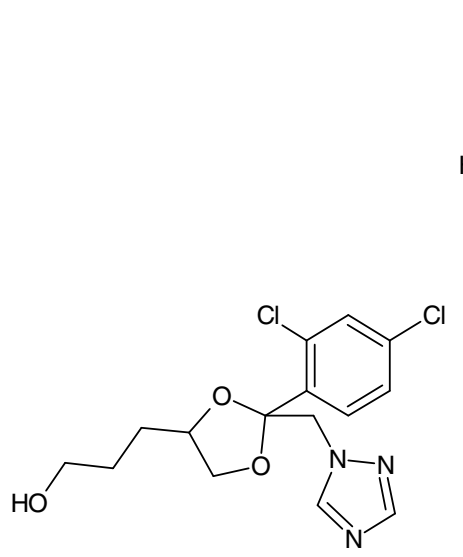

CGA 118245<smiles>CCCC1COC(Cn2cncn2)(c2ccc(Cl)cc2Cl)O1</smiles>

Propiconazole<smiles>CC(O)CC1COC(Cn2cncn2)(c2ccc(Cl)cc2Cl)O1</smiles>

CGA 118244<smiles>CCC(O)C1COC(Cn2cncn2)(c2ccc(Cl)cc2Cl)O1</smiles>

CGA 136735

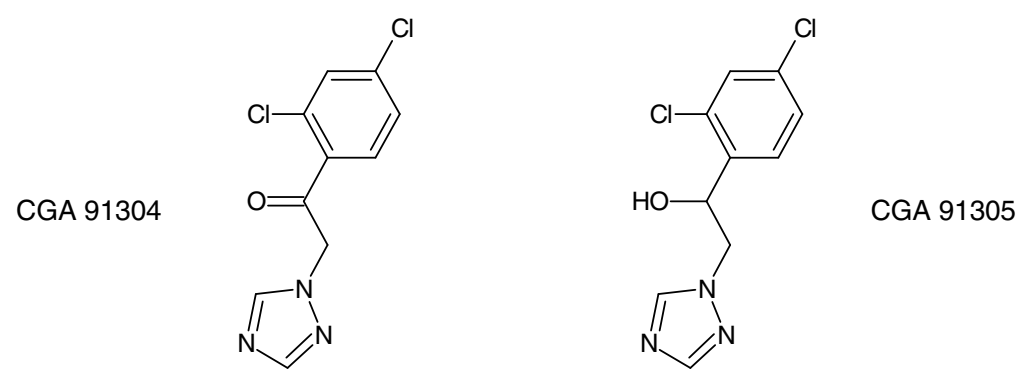

Fig. 1. Chemical structures of propiconazole and five of its metabolites. The chemical names of the metabolites are: CGA 118245, 3-(2-((1H-1,2,4-triazol-1-yl)methyl)-2-(2,4dichlorophenyl)-1,3-dioxolan-4-yl)propan-1-ol; CGA 118244, 1-(2-((1H-1,2,4-triazol-1-yl)methyl)-2-(2,4-dichlorophenyl)-1,3-dioxolan-4-yl)propan-2-ol; CGA 136735, 1-(2-((1H-1,2,4-triazol-1-yl)methyl)-2-(2,4-dichlorophenyl)-1,3-dioxolan-4-yl)propan-1-ol; CGA 91304, 1-(2,4-dichlorophenyl)-2-(1H-1,2,4-triazol-1-yl)ethanone; CGA 91305, 1-(2,4-dichlorophenyl)-2-(1H-1,2,4-triazol-1-yl)ethanol.

from light (NIH, 2001). The absorbance was measured at 540 and $690 \mathrm{~nm}$ on a Molecular Devices SpectraMax 340 spectrophotometer (Sunnyvale, CA). The percent of viable cells was then determined according to: Viability $(\%)=[($ A540-A690 of experimental well)-mean of (A540-A690 of blank control wells)]/[mean of (A540-A690 of vehicle control wells)- mean of (A540-A690 of blank control wells)]. The procedure for the HepG2 cells was the same as described above except the medium used was EMEM.

\subsubsection{MTT assay}

The cytotoxic effects of propiconazole and the propiconazole metabolites were determined by the MTT assay in Hepa1c1c7 and HepG2 cell lines and primary mouse hepatocytes using the method described by Gerlier and Thomasset (Gerlier and Thomasset, 1986) based on Mossman (Mosmann, 1983) with some modifications. Briefly, Hepa1c1c7 cells were seeded in 96-well plates at a density of $3 \times 10^{3}$ cells/well in $200 \mu \mathrm{L}$ of AMEM supplemented with $10 \% \mathrm{FBS}$, and incubated at $37{ }^{\circ} \mathrm{C}$ in $5 \% \mathrm{CO}_{2} / 95 \%$ air. When cells reached $60-70 \%$ confluence $(\sim 24 \mathrm{~h})$, non-adherent cells and serum-containing AMEM were removed and chemically-treated serum-free AMEM were applied. Chemical-treated stocks were initially prepared in acetone, and diluted with serum-free AMEM to the appropriate concentration for each experiment. The final acetone concentration did not exceed $0.5 \%$. The cells were then treated with various concentrations of the chemically-treated serum-free AMEM stocks for $24 \mathrm{~h}$. The MTT solution $(20 \mu \mathrm{L}, 5 \mathrm{mg} / \mathrm{ml})$ was added to each well $3 \mathrm{~h}$ prior to the end of the 24-h chemical treatment exposure period. The media was removed at the end of the 24-h exposure period. The insoluble purple formazan crystals were dissolved in $100 \mu \mathrm{L}$ DMSO/well and the absorbance was detected at $570 \mathrm{~nm}$ and $690 \mathrm{~nm}$ using a microplate SpectraMax 340 spectrophotometer. The cell viability percentage was calculated as follows: Viability $(\%)=[($ A570-A690 of experimental well)-mean of (A570-A690 of blank control wells)]/[mean of
(A570-A690 of vehicle control wells)-mean of (A570-A690 of blank control wells)]. The procedure for the HepG2 cells was the same as described above except the medium used was EMEM.

For primary mouse hepatocytes, the cold preservation media from each well was immediately replaced with fresh serum-free WEM, after receiving the cells. The hepatocytes were then acclimatized in a humidified $5 \% \mathrm{CO}_{2} / 95 \%$ air incubator at $37{ }^{\circ} \mathrm{C}$ overnight prior to use. The preparation of various concentrations of chemical solutions and the MTT assays of propiconazole and metabolites was described above. Briefly, the WEM was removed before dosing and then the mouse hepatocytes were treated for $48 \mathrm{~h}$ with chemical solutions prepared in serum-free WEM. The MTT solution was added to each well $3 \mathrm{~h}$ prior to the end of the exposure period. After $48 \mathrm{~h}$ of chemical exposure, the MTT containing media were removed, and the formazan crystals were dissolved in $100 \mu \mathrm{L}$ DMSO/well for the absorbance determinations as described above.

The cytotoxicity assays were carried out using six replicates at each concentration for HepG2 and Hepa1c1c7 cells and using individual studies on primary hepatocytes isolated from three mice. The highest concentration selected was $400 \mu \mathrm{M}$ based on solubility considerations. During the experimental period, all the wells were microscopically observed twice daily for cell mortality, chemical precipitation, and formazan formation. No visible precipitation of any test compound was found in any treatments at any of the endpoints. For each cell type, the controls consisted of a vehicle control with $0.5 \%$ acetone, a positive control, benzo[a]pyrene $(0.4-50 \mu \mathrm{M})$, and blank controls including cells without any chemical treatments and wells without cells. The study was repeated with propiconazole with separate sets of stock solutions.

\subsection{Data analysis}

Data are represented as mean $\pm \mathrm{SD}$. Statistical analyses were performed by one-way ANOVA followed by Dunnett's multiple 
comparison method using JMP 6.0 (SAS Institute, Cary, NC), or SigmaStat (SPSS, Chicago, IL). Student's t-tests were performed with SigmaStat. Differences between treatment and control groups were considered statistically significant at $p<0.05$. The concentrations of propiconazole that produced a $50 \%$ viability response with $95 \%$ confidence intervals (95\% C.I.s), and the statisti- cal comparisons of propiconazole MTT and neutral red concentration responses were determined using Prism software (GraphPad, San Diego, USA) where data were fitted to the Hill equation. Calculated $\log P$ (cLogP [ $\log$ of the octanol-water partition coefficient) estimates were calculated by ChemSketch V10.02 (ACD Labs, Toronto, ON).

Table 1

Comparison of the cytotoxic effects of propiconazole in Hepa1c1c7 and HepG2 cell lines using the MTT and Neutral red assays ${ }^{\mathrm{a}, \mathrm{b}}$

\begin{tabular}{|c|c|c|c|c|c|c|c|c|}
\hline \multirow[t]{3}{*}{ Propiconazole $(\mu \mathrm{M})$} & \multicolumn{4}{|c|}{ Hepa1c1c7 cells } & \multicolumn{4}{|c|}{ HepG2 cells } \\
\hline & \multicolumn{2}{|c|}{ MTT assay (\% Viability) } & \multicolumn{2}{|c|}{ Neutral red assay (\% Viability) } & \multicolumn{2}{|c|}{ MTT assay (\% Viability) } & \multicolumn{2}{|c|}{ Neutral red assay (\% Viability } \\
\hline & Mean & SD & Mean & SD & Mean & SD & Mean & SD \\
\hline 0 & 100 & & 100 & & 100 & & 100 & \\
\hline 25 & 83.5 & 8.3 & 100 & 12.6 & 106.5 & 18.3 & 68.1 & 10.5 \\
\hline 50 & 66.5 & 10.4 & 85.9 & 8.9 & $\mathrm{ND}^{\mathrm{c}}$ & $\mathrm{ND}^{\mathrm{c}}$ & 69 & 9.3 \\
\hline 100 & 55.1 & 4.1 & 83.7 & 10 & 106.7 & 15.9 & 76.4 & 9.5 \\
\hline 150 & 28.4 & 3.7 & 47.9 & 11.8 & 33.2 & 10.2 & 35.8 & 4.3 \\
\hline 200 & 2.9 & 1.5 & 1.4 & 1 & 37.4 & 16.6 & 12.7 & 2.0 \\
\hline
\end{tabular}

a The chemical treatment exposure time was $24 \mathrm{~h}$. Each mean and SD are the results of six replicate data points.

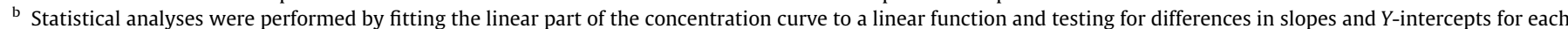

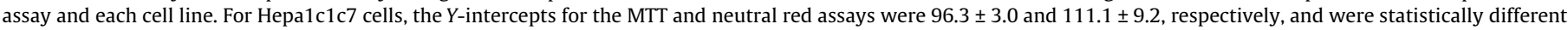

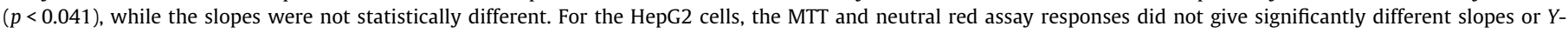
intercepts.

c ND, not determined.
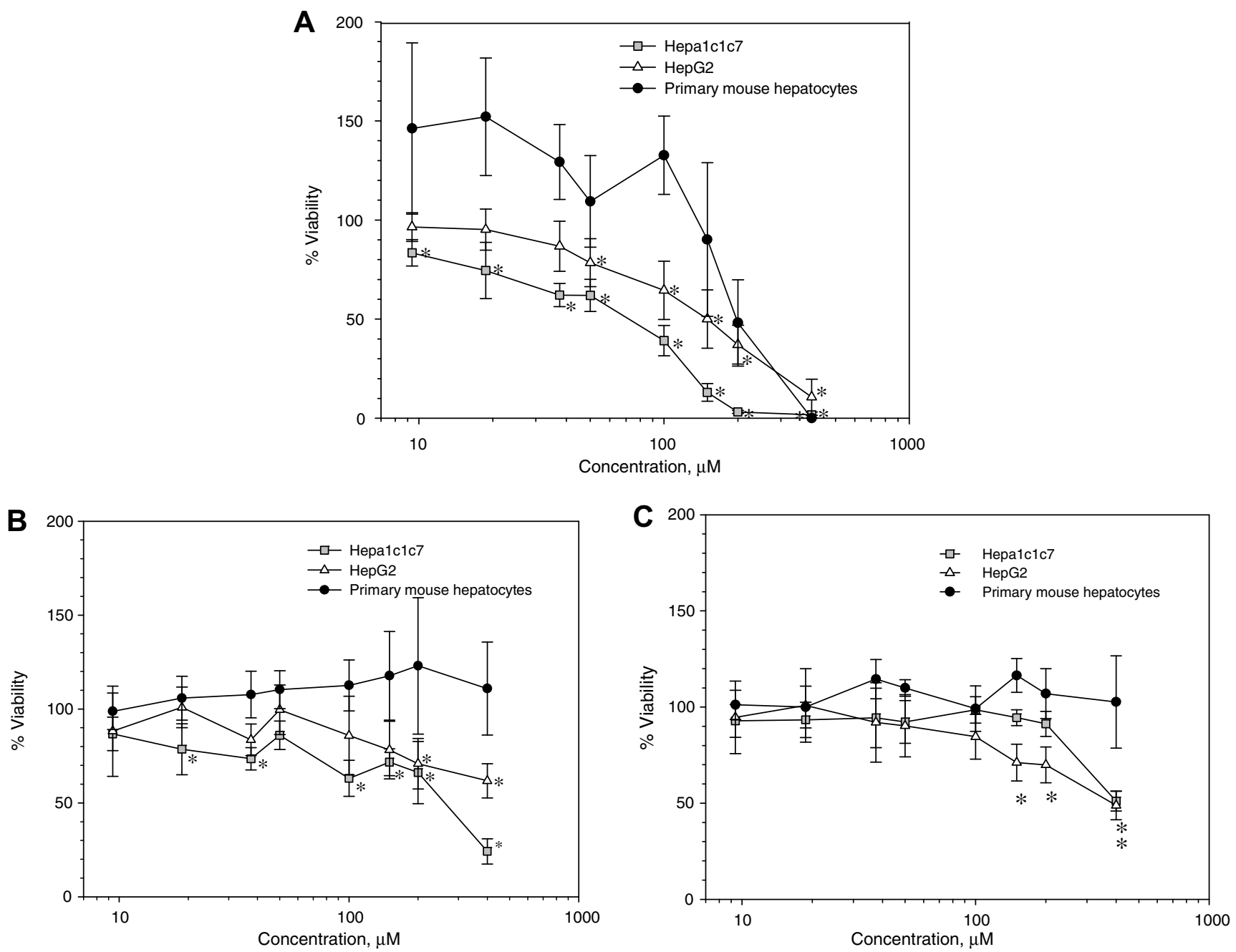

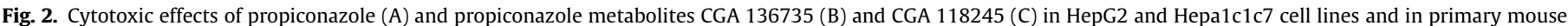

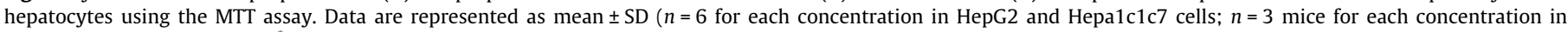
primary mouse hepatocytes). "Significantly different from the control by Dunnett's multiple comparison test $(p<0.05)$. 


\section{Results}

The results of the comparative sensitivity of the MTT and neutral red assays to detect propiconazole-induced cytotoxicity in Hepa1c1c7 and HepG2 cell lines are found in Table 1. Cells were treated for $24 \mathrm{~h}$ over a concentration range of 0-200 $\mu \mathrm{M}$. Concentration-related responses were evident in all four studies. The data were fitted to a linear function and tested for statistical differences between MTT and neutral red assays for each cell line. There were significant differences between the responses of the two vital dyes in the Hepa1c1c7 cells with the MTT assay being more sensitive to the cytotoxic effects of propiconazole. No statistical differences were detected between the MTT and neutral red assays using HepG2 cells. The MTT assay was chosen for the remainder of the cytotoxicity analyses based on the increased sensitivity in Hepa1c1c7 cells and on the ease of the assay procedure.

The cytotoxic effects of propiconazole and its metabolites were further evaluated in three hepatic cell types, Hepa1c7 and HepG2

Table 2

Cytotoxicity of propiconazole and five of its metabolites in liver cells at the highest concentration evaluated $(400 \mu \mathrm{M})^{\mathrm{a}}$

\begin{tabular}{|c|c|c|c|}
\hline Chemical & Hepa1c1c7 cells (\% Viability, mean \pm SD) & Primary mouse hepatocytes (\% Viability, mean \pm SD) & HepG2 cells (\% Viability, mean \pm SD) \\
\hline Propiconazole & $1.65 \pm 1.51^{\mathrm{b}, \mathrm{c}}$ & $0^{\mathrm{b}}$ & $10.6 \pm 9.1^{\mathrm{b}, \mathrm{c}}$ \\
\hline CGA 136735 & $24.2 \pm 6.7^{\mathrm{b}, \mathrm{d}}$ & $110.9 \pm 24.8$ & $61.8 \pm 9.1^{\mathrm{b}, \mathrm{d}}$ \\
\hline CGA 118245 & $51.1 \pm 5.1^{b}$ & $102.7 \pm 20$ & $48.9 \pm 7.5^{b}$ \\
\hline CGA 118244 & $64.3 \pm 16.4^{\mathrm{b}}$ & $112.2 \pm 20.1$ & $55.9 \pm 5.7^{\mathrm{b}}$ \\
\hline CGA 91304 & $76.1 \pm 6.3$ & $72.1 \pm 12.1$ & $75.5 \pm 14.9$ \\
\hline CGA 91305 & $86.1 \pm 26.2$ & $86.4 \pm 20.6$ & $82.2 \pm 16.8$ \\
\hline
\end{tabular}

a The chemical treatment exposure time was $24 \mathrm{~h}$ for Hepa1c1c7 and HepG2 cell lines and $48 \mathrm{~h}$ for primary mouse hepatocytes. Data are represented as the mean \pm SD

( $n=6$ for each concentration in HepG2 and Hepa1c1c7 cells; $n=3$ mice for each concentration in primary mouse hepatocytes).

b Significantly different from the control by Dunnett's multiple comparison test $(p<0.05)$.

c Significantly different from each other by Student's $t$-test $(p<0.05)$.

d Significantly different from each other by Student's $t$-test $(p<0.05)$.
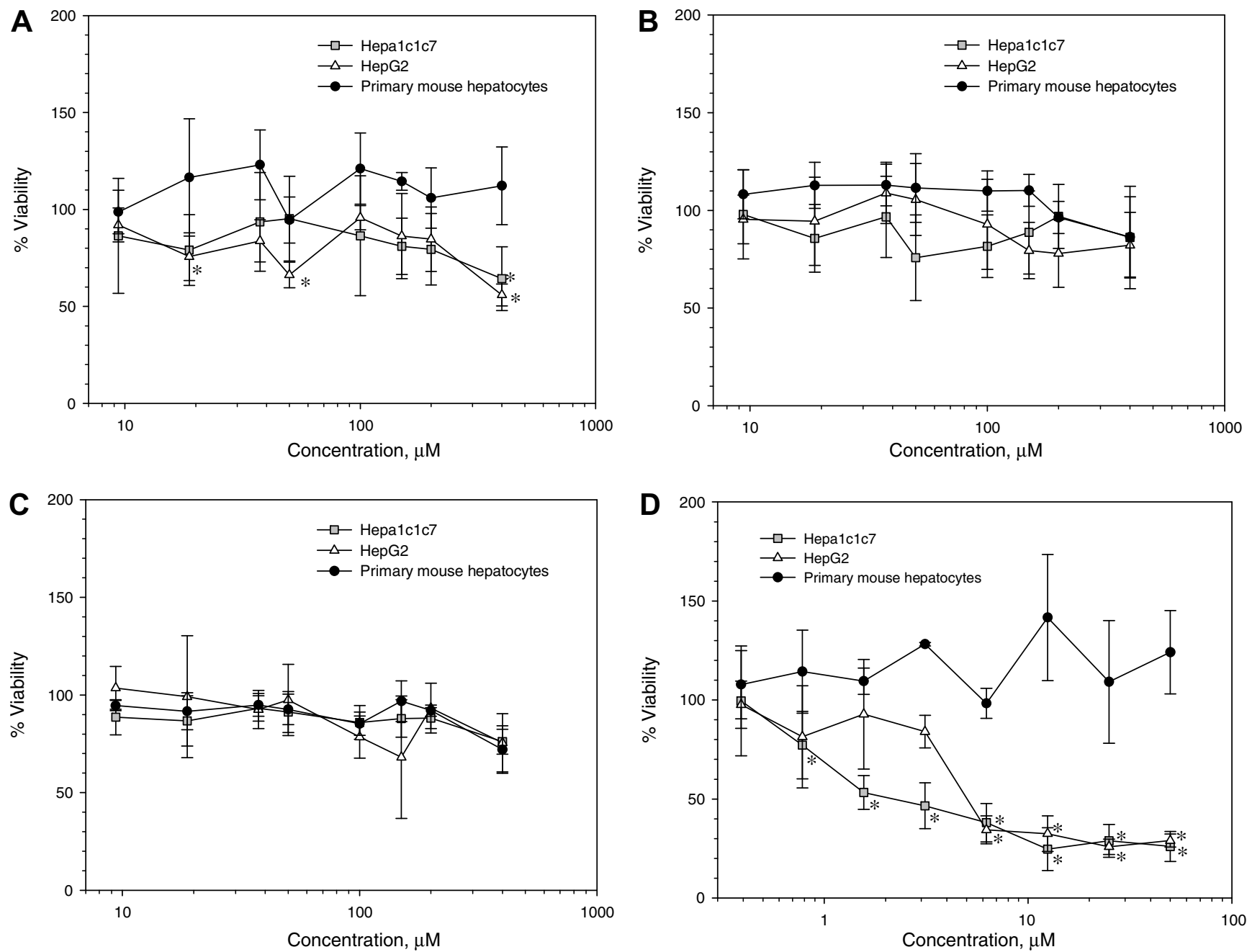

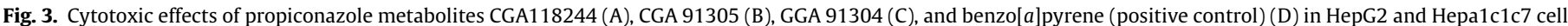

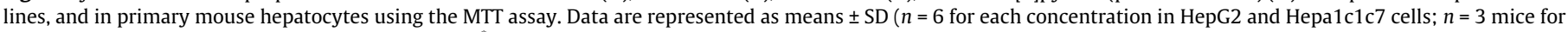
each concentration in primary mouse hepatocytes). "Significantly different from the control by Dunnett's multiple comparison test ( $p<0.05)$. 
cell lines, and primary male $\mathrm{CD}-1$ mouse hepatocytes using the MTT assay. Treatments were conducted in serum-free media to prevent the ability of serum proteins to bind to these agents and alter the results due to different amounts of unbound agents available in the media. Propiconazole demonstrated a clear concentration-related response in \% viability reduction in Hepa1c1c7 cells, HepG2 cells, and in primary mouse hepatocytes over a concentration range of $0-400 \mu \mathrm{M}$ for each cell type (Fig. $2 \mathrm{~A}$ ). The calculated concentrations that produced a $50 \%$ viability for Hepa $1 \mathrm{c} 1 \mathrm{c} 7$ cells was $85.4 \mu \mathrm{M}(95 \%$ C.I. $=62.9-116.0 \mu \mathrm{M})$, and for HepG2 cells was $148.4 \mu \mathrm{M}(95 \%$ C.I. $=126.7-173 \mu \mathrm{M})$. Analyses of these concentrations that gave a $50 \%$ viability response by the Student's $t$-test indicated that the values were statistically different from each other at $p<0.01$. Based on the dose response data, propiconazole exerted the highest cytotoxicity response in Hepa1c1c7 cells. Analysis of the cytotoxic responses of propiconazole in the three hepatic cell types at $400 \mu \mathrm{M}$ concentration indicated that propiconazole induced a $100 \%$ cytotoxic response in primary mouse hepatocytes, while Hepa1c1c7 cells were more sensitive than HepG2 cells to this agent (Table 2). Hepa1c1c7 cells were also more sensitive than HepG 2 cells to metabolite CGA 136735 the $\alpha$-hydroxylated metabolite of propiconazole (Fig. 2B, Table 2), while no observable effects in primary mouse hepatocytes were observed. Metabolite CGA 118245 the $\gamma$-hydroxylated metabolite of propiconazole exerted statistically significant effects on cell viability at several concentrations in Hepa1c1c7 cells (Fig. 2C) and similar significant effects in HepG2 cells at $400 \mu \mathrm{M}$ (Fig. 2C, Table 2). CGA 118245 had no effect in primary mouse hepatocytes. Propiconazole metabolite CGA 118244 , the $\beta$-hydroxylated metabolite of propiconazole was cytotoxic in both tumor cell lines (Fig. 3A, Table 2), with no effects on primary mouse hepatocytes. The two propiconazole metabolites, CGA 91304 and 91305, in which the dioxolone ring had been metabolically cleaved from the molecule had no statistically significant effects on cell viability in each of the hepatic cells evaluated (Fig. 3B and $\mathrm{C}$, Table 2). The positive control, benzo[a]pyrene, produced dose-dependent cytotoxic effects in Hepa1c1c7 and HepG2 cells at $0.7-50 \mu \mathrm{M}$. Benzo[a]pyrene did not induce significant cytotoxicity in primary mouse hepatocytes at the concentrations evaluated (Fig. 3D), possibly due the abbreviated incubation times as longer times are necessary to obtain full induction of the Cyp1a1 and Cyp1b1 needed to metabolize benzo[a]pyrene to its cytotoxic intermediates (Michalopoulos et al., 1976; Hengstler et al., 2000). A comparison of the effects of propiconazole and its five metabolites on the viability of the three hepatocellular cell types at the same molar concentration $(400 \mu \mathrm{M})$ suggests that the ranking of the six agents in both Hepa1c1c7 cells and HepG2 cells were similar with the exception of CGA 136735 which was ranked second in cytotoxicity in the Hepa1c1c7 cells and fourth in the HepG2 cells (Table 2). While all three hepatic cell types responded to propiconazole, only the two tumor cell lines were sensitive to the cytotoxic effects of the three of the metabolites.

\section{Discussion}

The triazole-containing conazole class of fungicides has been reported to undergo metabolic transformations including side chain hydroxylation, aromatic ring hydroxylation, sulfate, and glucuronide conjugation. Many triazole-containing conazoles are also metabolized to free triazole, triazoylalanine, and triazolyacetic acid (Schermerhorn et al., 2005). The metabolism of propiconazole has been studied in several species: Rat, mouse, and goat. In general, metabolism occurs at the propyl side chain, at the dioxolone ring, and with the release of free triazole (INCHEM, 1987). To date, there have been no reported studies on the cytotoxic effects of many of these metabolites. While metabolism can be a detoxification pro- cess converting lipophilic agents to their water soluble forms, metabolism can also be a toxification process converting inactive parent molecules to reactive toxic forms. Our goal was to use two tumorigenic hepatocellular cell lines and primary mouse hepatocytes to evaluate the cytotoxic effects of propiconazole and five of its metabolites to identify whether metabolism was a toxification or detoxification process for propiconazole for each cell type. For propiconazole, the most sensitive cell line was the mouse tumor cell line Hepa1c1c7, an interesting finding as propiconazole induces mouse liver tumors as reported from a 2-year feeding study (INCHEM, 1987). While propiconazole exerted cytotoxic effects in primary mouse hepatocytes, none of the five metabolites were cytotoxic in these cells. Primary hepatocytes contain active glucuronyl transferases which could conjugate the hydroxylated metabolites to more water soluble and less toxic forms. The levels of these enzymes are generally higher in primary cells than in transformed tumor cells (Smith et al., 2005; Westerink and Schoonen, 2007).

A recent toxicogenomic analysis of hepatic tissues from mice treated with propiconazole revealed significant increases in hepatic cell proliferation, hypertrophy, and CYP enzyme activities (Allen et al., 2006). Microarray analyses of these hepatic tissues indicated alterations in the expression of oxidative stress genes, cell cycle and cell proliferation genes, and signaling pathways (Ward et al., 2006). Propiconazole induced the over-expression of a number of oxidative stress related genes including aldo-keto reductases, aminolevulinic acid synthase, heat shock proteins, glutathione transferases, UDP glucuronyl transferases, and sulfotransferases (Ward et al., 2006). There are known relationships between oxidative stress and toxicity and oxidative stress and carcinogenesis. Increased cellular oxidant levels can alter proteins, lipids, and nuclear and mitochondrial DNA as well as alter cell growth regulatory pathways (Klaunig and Kamendulis, 2004). Furthermore, cellular stresses induced by chemicals can cause mammalian cell death via endogenous reactive oxygen species (ROS) (see (Kobayashi et al., 2002) and references therein). In a related cytotoxicity study of ketoconazole using primary rat hepatocytes, Rodriguez and Acosta proposed that the cytotoxic effects of ketoconazole could be related to its ability to inhibit cholesterol biosynthesis through the inhibition of lanosterol $14 \alpha$-demethylase. Cholesterol is a major component of membranes in animals and its depletion would result in the loss of plasma membrane integrity (Rodriguez and Acosta, 1995). Inhibition of lanosterol $14 \alpha$-demethylase also results in the accumulation of toxic oxysterol intermediates (Guardiola et al., 1996). We have shown that propiconazole can decrease serum cholesterol levels in mice which could result in oxysterol formation and decreased plasma membrane integrity (Allen et al., 2006). Rodriguez and Acosta also studied the inhibitory action of azoles in rat liver mitochondria and found that ketoconazole and other conazoles inhibited complex I of the respiratory chain reducing ATP formation which could explain their hepatotoxic action (Rodriguez and Acosta, 1996). At present, the mechanisms of hepatic toxicity of propiconazole and its metabolites in mouse liver or mouse liver cells have not yet been elucidated although ROS formation, inhibition of cholesterol biosynthesis, oxysterol formation, inhibition of mitochondrial function and alterations in signaling pathways are viable possibilities.

Of the many physicochemical measures of chemicals, LogP, the logarithm of the partition coefficient, the ratio of the solubility of a compound between octanol and water, has been studied extensively with regard to toxicity. LogP describes the lipophilicity of a chemical and has been found to be correlated with cytotoxic, mutagenic, and carcinogenic activities of chemicals (Debnath et al., 1994; Bradbury, 1995; Franke et al., 2001; Smith et al., 2002). Studies in fish (Lu et al., 2005) and other organisms (Miyazaki et al., 2002) have shown a linear increase in toxicity for a series of 


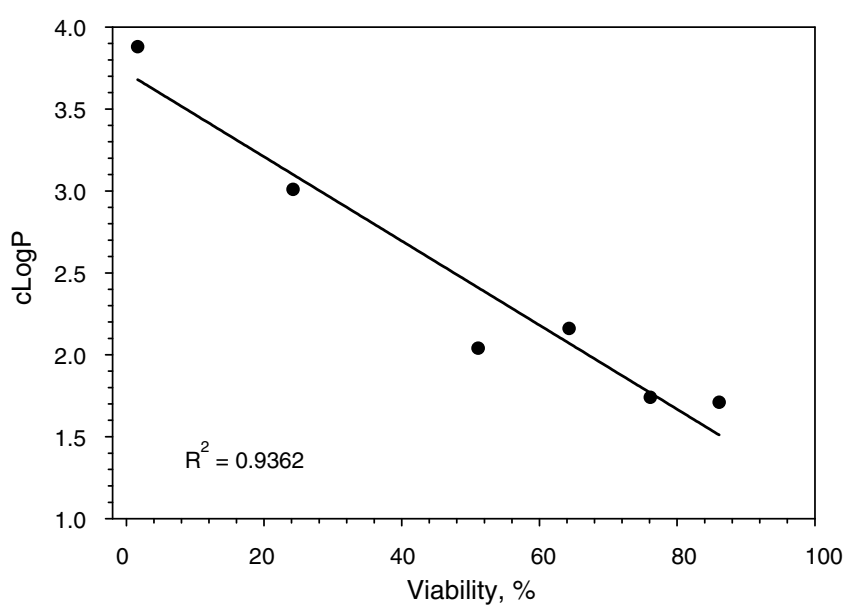

Fig. 4. Linear relationship between the viability of propiconazole and its metabolites in Hepa1c1c7 cells and cLogP estimates of the agents.

compounds as LogP increases. In rat liver hepatocytes a direct relationship was reported between $\mathrm{LC}_{50}$ and $\log \mathrm{P}$ for a series of 31 phenols (Moridani et al., 2003). We have shown that a linear relationship exists between the viability response of six propiconazole agents in Hepa1c1c7 cells and their calculated $\log \mathrm{P}(\mathrm{cLogP})$ values (Fig. 4), that is, as cLogP increases, viability decreases. Chemicals with higher cLogP values are more likely to cross biomembranes, and interact with biological macromolecules such as enzymes and DNA and therefore have a greater potential to exert toxic activities (Smith et al., 2002).

The relationships between toxicity and carcinogenesis are complex. Many of the same insults that lead to toxicity can also lead to tumorigenesis. DNA and protein damage, modified gene expression, and altered signaling pathways are some examples of these insults. We found that none of the propiconazole metabolites were cytotoxic to primary mouse hepatocytes, while several of the propiconazole metabolites were cytotoxic to tumor cells; however, their responses were less than that of the parent molecule, propiconazole. The role of the propiconazole metabolites in the mouse liver propiconazole tumorigenesis process has yet to be determined.

In summary, we conclude that these propiconazole metabolites would not contribute to the propiconazole-induced cytotoxicity process in primary mouse hepatocytes and therefore metabolism of propiconazole is a detoxification event. Our results using hepatotumorigenic cell lines suggest that in the in vivo propiconazole hepatotumorigenesis process, incipiently formed tumor cells would be more susceptible to the cytotoxic effects of the parent propiconazole compared to the propiconazole metabolites.

\section{Acknowledgments}

We thank Doug Wolf, Susan Hester, and Julian Preston for their excellent reviews of the manuscript. We thank Kathleen Wallace for her assistance with the cell culture assays. We also thank Dr. John Kenneke of the US EPA, National Exposure Research Laboratory-Athens for the propiconazole metabolites. This research was performed while P.-J. Chen held a National Research Council Associateship Award at the US EPA.

\section{References}

Allen, J.W., Wolf, D.C., George, M.H., Hester, S.D., Sun, G., Thai, S.F., Delker, D.A., Moore, T., Jones, C., Nelson, G., Roop, B.C., Leavitt, S., Winkfield, E., Ward, W.O. Nesnow, S., 2006. Toxicity profiles in mice treated with hepatotumorigenic and non-hepatotumorigenic triazole conazole fungicides: propiconazole, triadimefon, and myclobutanil. Toxicol. Pathol. 34, 853-862.
Borenfreund, E., Puerner, J.A., 1984. A simple quantitative procedure using monolayer culture for toxicity assays. J. Tissue Cult. Method 9, 7-9.

Bradbury, S.P., 1995. Quantitative structure-activity relationships and ecological risk assessment: an overview of predictive aquatic toxicology research. Toxicol. Lett. 79, 229-237.

Debnath, A.K., Shusterman, A.J., Lopez de Compadre, R.L., Hansch, C., 1994 International commission for protection against environmental mutagens and carcinogens. The importance of the hydrophobic interaction in the mutagenicity of organic compounds. Mutat Res 305, 63-72.

Franke, R., Gruska, A., Giuliani, A., Benigni, R., 2001. Prediction of rodent carcinogenicity of aromatic amines: a quantitative structure-activity relationships model. Carcinogenesis 22, 1561-1571.

Gerlier, D., Thomasset, N., 1986. Use of MTT colorimetric assay to measure cell activation. J. Immunol. Methods 94, 57-63.

Green, T., Lee, R., Moore, R.B., Ashby, J., Willis, G.A., Lund, V.J., Clapp, M.J., 2000. Acetochlor-induced rat nasal tumors: further studies on the mode of action and relevance to humans. Regul. Toxicol. Pharmacol. 32, 127-133.

Green, T., Toghill, A., Lee, R., Waechter, F., Weber, E., Noakes, J., 2005 a. Thiamethoxam induced mouse liver tumors and their relevance to humans. Part 1: mode of action studies in the mouse. Toxicol. Sci. 86, 36-47.

Green, T., Toghill, A., Lee, R., Waechter, F., Weber, E., Peffer, R., Noakes, J., Robinson, M., 2005b. Thiamethoxam induced mouse liver tumors and their relevance to humans. Part 2: Species differences in response. Toxicol. Sci. 86, 48-55.

Guardiola, F., Codony, R., Addis, P.B., Rafecas, M., Boatella, J., 1996. Biological effects of oxysterols: current status. Food. Chem. Toxicol. 34, 193-211.

Hakoi, K., Cabral, R., Hoshiya, T., Hasegawa, R., Shirai, T., Ito, N., 1992. Analysis of carcinogenic activity of some pesticides in a medium-term liver bioassay in the rat. Teratogen. Carcin. Mut. 12, 269-276.

Hengstler, J.G., Utesch, D., Steinberg, P., Platt, K.L., Diener, B., Ringel, M., Swales, N. Fischer, T., Biefang, K., Gerl, M., Bottger, T., Oesch, F., 2000. Cryopreserved primary hepatocytes as a constantly available in vitro model for the evaluation of human and animal drug metabolism and enzyme induction. Drug. Metab. Rev. 32, 81-118.

INCHEM, 1981. Monograph 566. Triadimefon. In: Pesticide Residues in Food: 1981 Evaluations, p. 36.

INCHEM, 1987. Monograph 768. Propiconazole Part II Toxicology. In: Pesticide residues in food: 1987 Evaluations, p. 19

INCHEM, 1997. Monograph 930. Fenbuconazole: Part II Toxicological \& Environmental. In: Pesticide Residues in Food -1997, p. 49.

INCHEM, 2001. Toxicological evaluations IMAZILIL (Addendum). In, JMPR Monographs 2001, p. 25.

Klaunig, J.E., Kamendulis, L.M., 2004. The role of oxidative stress in carcinogenesis. Annu. Rev. Pharmacol. Toxicol. 44, 239-267.

Kobayashi, D., Kondo, K., Uehara, N., Otokozawa, S., Tsuji, N., Yagihashi, A Watanabe, N., 2002. Endogenous reactive oxygen species is an important mediator of miconazole antifungal effect. Antimicrob. Agents and Chemother. $46,3113-3117$.

Lu, G.H., Wang, C., Yuan, X., Lang, P.Z., 2005. Quantitative structure-activity relationships for the toxicity of substituted benzenes to Cyprinus carpio. Biomed. Environ. Sci. 18, 53-57.

Michalopoulos, G., Sattler, G., Sattler, C., Pitot, H.C., 1976. Interaction of chemical carcinogens and drug-metabolizing enzymes in primary cultures of hepatic cells from the rat. Am. J. Pathol. 85, 755-772.

Miller, J.A., Miller, E.C., 1983. Some historical aspects of N-aryl carcinogens and their metabolic activation. Environ. Health Perspect. 49, 3-12.

Miyazaki, A., Amano, T., Saito, H., Nakano, Y., 2002. Acute toxicity of chlorophenols to earthworms using a simple paper contact method and comparison with toxicities to fresh water organisms. Chemosphere 47, 65-69.

Moridani, M.Y., Siraki, A., O’Brien, P.J., 2003. Quantitative structure toxicity relationships for phenols in isolated rat hepatocytes. Chem. Biol. Interact. 145 213-223.

Mosmann, T., 1983. Rapid colorimetric assay for cellular growth and survival: application to proliferation and cytotoxicity assays. J. Immunol. Methods 65 55-63.

$\mathrm{NIH}, 2001$. Guidance document on using in vitro data to estimate in vivo starting doses for acute toxicity. NIH Publication No: 01-4500.

Pastoor, T., Rose, P., Lloyd, S., Peffer, R., Green, T., 2005. Case study: weight of evidence evaluation of the human health relevance of thiamethoxam-related mouse liver tumors. Toxicol. Sci. 86, 56-60.

Pesticideinfo.org, 2008. Propiconazole. <www.pesticideinfo.org>.

Rodriguez, R.J., Acosta Jr., D., 1995. Comparison of ketoconazole- and fluconazoleinduced hepatotoxicity in a primary culture system of rat hepatocytes. Toxicology 96, 83-92.

Rodriguez, R.J., Acosta Jr., D., 1996. Inhibition mitochondrial function in isolated rat liver mitochondria by azole antifungals. J. Biochem. Toxicol. 11, 127-131.

Schermerhorn, P.G., Golden, P.E., Krynitsky, A.J., Leimkuehler, W.M., 2005 Determination of 22 triazole compounds including parent fungicides and metabolites in apples, peaches, flour, and water by liquid chromatography tandem mass spectrometry. J. AOAC Int. 88, 1491-1502.

Smith, C.J., Perfetti, T.A., Morton, M.J., Rodgman, A., Garg, R., Selassie, C.D., Hansch, C., 2002. The relative toxicity of substituted phenols reported in cigarette mainstream smoke. Toxicol. Sci. 69, 265-278.

Smith, C.M., Graham, R.A., Krol, W.L., Silver, I.S., Negishi, M., Wang, H., Lecluyse, E.L. 2005. Differential UGT1A1 induction by chrysin in primary human hepatocytes and HepG2 Cells. J. Pharmacol. Exp. Ther. 315, 1256-1264. 
Sun, G., Thai, S.F., Tully, D.B., Lambert, G.R., Goetz, A.K., Wolf, D.C., Dix, D.J., Nesnow, S., 2005. Propiconazole-induced cytochrome P450 gene expression and enzymatic activities in rat and mouse liver. Toxicol. Lett. 155, 277-287.

Ward, W.O., Delker, D.A., Hester, S.D., Thai, S.F., Wolf, D.C., Allen, J.W., Nesnow, S., 2006. Transcriptional profiles in liver from mice treated with hepatotumorigenic and nonhepatotumorigenic triazole conazole fungicides: propiconazole, triadimefon, and myclobutanil. Toxicol. Pathol. 34, 863-878.
Westerink, W.M., Schoonen, W.G., 2007. Phase II enzyme levels in HepG2 cells and cryopreserved primary human hepatocytes and their induction in HepG2 cells. Toxicol. In Vitro 21, 1592-1602.

Xue, W., Warshawsky, D., 2005. Metabolic activation of polycyclic and heterocyclic aromatic hydrocarbons and DNA damage: a review. Toxicol. Appl. Pharmacol. 206, 73-93. 